\title{
Corrigendum: The role of process analysis and expert consultation in implementing an electronic medical record solution for multidrug-resistant tuberculosis
}

\author{
Authors: \\ Harsha Desai ${ }^{1}$ \\ Rubeshan Perumal ${ }^{2}$ \\ Rosemary Quiling ${ }^{3}$ \\ Yashik Singh ${ }^{4}$

\section{Affiliations:} \\ ${ }^{1}$ Department of Health \\ Informatics, School of \\ Nursing and Public Health, \\ University of KwaZulu-Natal, \\ South Africa

\section{${ }^{2}$ Centre for the AIDS \\ Programme of Research \\ in South Africa (CAPRISA), \\ University of KwaZulu-Natal, \\ South Africa \\ ${ }^{3}$ Discipline of Information \\ Systems \& Technology, \\ School of Management, \\ IT \& Governance, College of Law \& Management Studies, University of KwaZulu-Natal, \\ Durban, South Africa}

${ }^{4}$ Department of Telehealth, School of Nursing and Public Health, University of KwaZulu-Natal, Durban, South Africa

\section{Correspondence to:}

Rubeshan Perumal

\section{Email:}

rubeshanperumal@gmail.

com

Postal address:

Centre for the AIDS

Programme of Research

in South Africa (CAPRISA),

University of KwaZulu-Natal,

Durban 4000, South Africa

\section{Dates:}

Published: 15 Jan. 2014
Read online:
In the title column on page 1 , the names of two contributing authors to this article have been erroneously omitted. In addition, the order of the listed authors of this article has also been rearranged. The correct order list, affiliations, and authors' contributions of the article is provided below:

\section{Authors:}

Harsha Desai ${ }^{1}$

Rubeshan Perumal ${ }^{2}$

Rosemary Quiling ${ }^{3}$

Yashik Singh ${ }^{4}$

\section{Affiliations:}

${ }^{1}$ Department of Health Informatics, School of Nursing and Public Health, University of KwaZuluNatal, South Africa

${ }^{2}$ Centre for the AIDS Programme of Research in South Africa (CAPRISA), University of KwaZuluNatal, South Africa

${ }^{3}$ Discipline of Information Systems \& Technology, School of Management, IT \& Governance, College of Law \& Management Studies, University of KwaZulu-Natal, Durban, South Africa

${ }^{4}$ Department of Telehealth, School of Nursing and Public Health, University of KwaZulu-Natal, Durban, South Africa

\section{Authors' contributions:}

R.P. (University of KwaZulu-Natal) and H.D. (University of KwaZulu-Natal) developed the concept for the study and conducted the process analysis. H.D. conducted the Delphi study. H.D. and R.P. analysed the data from both study phases, and contributed to the writing of this manuscript. R.Q. (University of KwaZulu-Natal) and Y.S. (University of KwaZulu-Natal) guided the design and write-up of the study.

How to cite this article: Desai, H., Perumal, R., Quiling, R. \& Singh, Y., 2014, 'Corrigendum: The role of process analysis and expert consultation in implementing an electronic medical record solution for multidrug-resistant tuberculosis', SA Journal of Information Management 16(1), Art. \#617, 8 pages. http://dx.doi.org/10.4102/sajim.v16i1.617-1

Note: Doi of original article: http://dx.doi.org/10.4102/sajim.v16i1.617

Copyright: @ 2014. The Authors. Licensee: AOSIS OpenJournals. This work is licensed under the Creative Commons Attribution License. 